\title{
Environmental Policy, North-South Trade and FDI
}

\author{
Juan Carlos Bárcena-Ruiz* and María Begoña Garzón
}

\begin{abstract}
In this paper we analyze trade between two countries, called the North and the South. Each country owns one firm and production costs are lower in the South. To serve foreign markets firms may export or engage in FDI. Both countries set tariffs on imported goods. When only the North sets an environmental tax, both firms engage in FDI if the difference in costs between the two countries is low enough, otherwise the South exports and the North engages in FDI. Although production costs are lower in the South, the implementation of an environmental policy permits the North to obtain greater welfare. If the South also sets an environmental tax, both countries always engage in FDI and the South obtains greater welfare than the North. Thus, stringent environmental policies by the South do not restrict FDI by Northern firms, encourage FDI by domestic firms, reduce its environmental damage and increase its welfare. Although this reduces social welfare in the North, joint welfare increases.
\end{abstract}

Keywords: environmental tax, tariff, FDI, export, imperfect competition JEL classification: L22, Q56, Q58.

* Corresponding author: J.C. Bárcena-Ruiz. Departamento de Fundamentos del Análisis Económico I, Facultad de Ciencias Económicas y Empresariales, Universidad del País Vasco, UPV/EHU. Avenida Lehendakari Aguirre 83, 48015 Bilbao, Spain. Phone: 34 + 9460138 15; Fax: 34 + 9460138 91. Emails: juancarlos.barcena@ehu.es, mariabegona.garzon@ehu.es

Financial support from Ministerio de Ciencia y Tecnología (ECO2012-32299) is gratefully acknowledged 


\section{Introduction}

Foreign Direct Investment (FDI) has spread rapidly through the world economy in the past two decades (see UNCTAD, 2013). During the 1980s FDI flows increased to take advantage of lower costs of product assembly in developing economies and to access new markets. ${ }^{1}$ Such economies tend to have lax environmental policies and so they are at a risk of becoming a pollution haven for foreign firms. ${ }^{2}$ Thus, developing economies need to assess the possibility of implementing environmental policies when foreign polluting firms locate in their countries. The analysis of this issue is the objective of the paper.

The relationship between trade and the location decision of polluting firms has been profusely analyzed in the relevant literature (see, for example, Rauscher, 1995; Markusen et al., 1995; Markusen, 1997; Bárcena-Ruiz and Garzón, 2003; Kayalica and Lahiri, 2005). These studies show that the environmental policy implemented by governments affects their environments and the locations of firms. However, they do not consider when analyzing North-South trade that there are other factors, such as the difference in production costs or technology transfers, that influence firms when they decide whether to engage in FDI or not. There are studies that focus explicitly on the linkage between pollution and international trade considering North-South trade. In this regard, Copeland and Taylor $(1994,1995)$ find that free trade improves the environment of developed countries but worsens that of developing ones. Chichilnisky (1994) argues that differences in property rights create a motive for trade between otherwise identical regions. The South has ill-defined property rights on environmental resources, which results in over-exploitation of resources and leads to environmental deterioration. By considering that the South has a worse abatement technology than the North, Abe and Zhao (2005) analyze welfare effects of emission taxes when the Northern firm chooses between an international joint venture and FDI. They find that if the South has a poor (good) abatement technology its best policy is to impose a high (low) emission tax which means that firms engage in FDI (prefer joint ventures).

Celik and Orbay (2011) analyze North-South trade assuming two countries each of which has one firm. The Southern firm is less efficient than the Northern one. They focus on environmental damage caused by firms under asymmetric information: the environmental damage caused by the Southern firm is publicly known but there is uncertainty about the damage caused by the Northern firm. The South sets an 
environmental tax to protect its environment and a tariff to protect its firm. The North does not set tariffs. The Northern firm may engage in FDI in the South or stay at home and export to the South. They find that the developing country may be better off encouraging FDI if the marginal damage from pollution is sufficiently low. Otherwise, the South sets a tax that motivates the North to export.

This paper analyzes whether firms engage in FDI or not, focusing on the difference in production costs between countries and on the policies that they implemented to protect their environments and domestic markets. We consider two countries, the North and the South, each of which has one firm. Each firm owns two plants and each plant produces a different good. Markets are segmented. ${ }^{3}$ In order to serve the domestic market each firm has a plant in its home market. To serve foreign markets firms have two options: they may set up a plant in their home country and export its output or set up a plant in the foreign country and produce the good there. ${ }^{4}$ First we assume that only the North sets an environmental tax, and both countries set a tariff on imported goods to protect their domestic firms. Later we assume that the South also implements an environmental policy.

Our paper is related with that of Celik and Orbay (2011). The main difference is that we consider that both firms may engage in FDI while they assume that only the Northern firm engages in FDI. ${ }^{5}$ Other differences are as follows. First, as in many papers analyzing North-South trade we assume that it is cheaper to produce in the South. Second, we assume initially that the South does not protect the environment. ${ }^{6}$ Third, we consider that both countries set tariffs. Finally, there is no uncertainty in our model.

We find that when only the North sets an environmental tax both firms engage in FDI, setting up a plant in each country if the difference in costs between the two countries is low enough. This result may help to explain in part why firms from developing countries engage in FDI in developed ones. In that case, although by engaging in FDI the Southern firm pays an environmental tax, abates emissions and incurs a higher production cost, the tariff that it pays to export has a stronger negative effect on profits. The Northern firm engages in FDI to avoid the tariff, the environmental tax and the abatement costs, and to reduce production costs. If the difference in costs is high enough the Northern firm engages in FDI and the Southern firm exports and thus there is one plant in the North and three plants in the South. In both cases the North obtains greater welfare and suffers less environmental damage than 
the South. Note that when the difference in costs is high the South suffers more environmental damage since there are three polluting plants there while in the other case there are only two. Although the North has greater production costs it obtains greater welfare since it implements an environmental policy.

We extend the model to consider that both countries set environmental taxes, and find that in equilibrium both firms always engage in FDI. ${ }^{7}$ Therefore, when both countries set environmental taxes, the Southern firm engages in FDI for a greater range of parameter values than when only the North sets such taxes. This means that environmental policies from the South encourage FDI by domestic firms without restricting FDI by foreign firms. Finally, when the two countries set environmental taxes the North obtains lower welfare than the South, and the North (South) obtains lower (greater) welfare than when only the North sets such taxes. This means that the South could reduce its environmental damage and increase its welfare by implementing policies to protect its environment. Although this reduces welfare in the North, joint welfare is greater when both countries set environmental taxes. This result may help to explain in part why developing countries are setting stringent environmental policies.

The rest of the paper is organized as follows. Section 2 describes the model. Section 3 presents results for the case when only the North set environmental taxes. Section 4 extends the model to assume that both countries set environmental taxes and Section 5 concludes.

\section{The Model}

We consider an economy comprising two countries, the North and the South, denoted respectively by $N$ and $S$. Markets are segmented and there are two firms (one owned by each country) that serve both markets. The firm owned by investors from country $k$ is denoted as firm $k(k=N, S)$. Each firm manufactures two products: product 1 is sold in country $N$ and product 2 is sold in country $S$. In order to serve domestic consumers each firm has a plant in its home market. To sell to foreign consumers firms have two options: they may set up a plant in their home country and export the product or they may set up a plant in the foreign country and produce the good there. We consider that in order to 
protect domestic firms from international competition each government sets a tariff on imported goods; ${ }^{8}$ we denote this tariff by $\tau_{k}, k=N, S$.

Consumers may buy the product from either a domestic or a foreign firm. The inverse demand function in each country is:

$$
p_{i}=\alpha-q_{i N}-q_{i S}, i=1,2 \text {, }
$$

where $p_{i}$ is the price of product $i$, and $q_{i k}$ is the output level of plant $i$ by firm $k$ (plant $i k$ ), $i=1,2 ; k=N, S$.

The technology used by both firms in both their plants is the same. We assume that production costs in country $N$ are higher than in country $S .{ }^{9}$ When a plant is located in country $N$ its marginal production cost is $c$, and when it is located in country $S$ its marginal production cost is normalized to 0 ; therefore, $c$ can be interpreted as the difference in production costs between the two countries. We assume that $c<\bar{c}$, where $\bar{c}=\alpha / 4$, to ensure that the output level of the plants located in country $N$ is positive in all cases.

Each unit of good produced in each plant causes one unit of pollutant. Although pollution reduces the welfare of country $S$, we assume initially that this country does not implement an environmental policy to control pollution (in Section 4 we consider that both countries implement an environmental policy). The government of $N$ sets a tax, $t_{N}$, per unit of pollutant emitted to make the plants located there internalize the negative externality. Producers have technology available for abating pollutant emissions. If plant $i k$ is located in country $N$ it chooses output level $q_{i k}$ and pollution abatement level $a_{i k}$, and its pollutant emissions are $e_{i k}=q_{i k}-a_{i k}$; thus, total taxes paid by this plant are $t_{N} e_{i k}$. The total pollution abatement cost of plant $1 k$ is: $C\left(a_{i k}\right)=d\left(a_{i k}\right)^{2} / 2$. As country $S$ does not set environmental taxes, plants located in country $S$ do not abate emissions.

The profit of firm $k$ is the sum of the profits obtained by its two plants: $\pi_{k}=\pi_{1 k}+\pi_{2 k}$, $k=N$, S. Specifically, if firm $N$ exports its profit is given by:

$$
\pi_{N}=\pi_{1 N}+\pi_{2 N}=\left[\left(p_{1}-c\right) q_{1 N}-t_{N} e_{1 N}-d\left(a_{1 N}\right)^{2} / 2\right]+\left[\left(p_{2}-c-\tau_{S}\right) q_{2 N}-t_{N} e_{2 N}-d\left(a_{2 N}\right)^{2} / 2\right],
$$


where $\tau_{S}=t_{N}=a_{2 N}=c=0$ in $\pi_{2 N}$ if firm $N$ engages in FDI. ${ }^{10}$ The profit of firm $S$ is given by:

$$
\pi_{S}=\pi_{1 S}+\pi_{2 S}=\left[\left(p_{1}-c-\tau_{N}\right) q_{1 S}-t_{N} e_{1 S}-d\left(a_{1 S}\right)^{2} / 2\right]+\left[p_{2} q_{2 S}\right]
$$

where $t_{N}=a_{1 S}=c=0$ if firm $S$ exports, and $\tau_{N}=0$ if it engages in FDI.

Given that firm $k$ is owned by investors from country $k$, the producer surplus in that country is given by: $P S_{k}=\pi_{k}, k=N, S$. As markets are segmented, the consumer surplus in country $k$ is given by: $C S_{k}=\left(q_{i N}+q_{i S}\right)^{2} / 2$, where $i=1$ if $k=N$ and $i=2$ if $k=S$.

Given that each firm may export products to the foreign country (denoted by $E$ ) or engage in FDI there (denoted by $F$ ), four cases are considered: both firms export $(E E)$, both firms set up a plant in the foreign country $(F F)$, only firm $N$ exports, and only firm $S$ exports. In the last two cases, we denote by $E F$ the firm that exports and by $F E$ the firm that engages in FDI.

The total taxes and tariffs collected by government $k, T_{k}$, comprise the environmental taxes paid by the firms located in the country and the tariffs paid by imported goods, if any. Thus, if both firms export then $T_{N}=t_{N}\left(e_{1 N}+e_{2 N}\right)+\tau_{N} q_{1 S}$ and $T_{S}=\tau_{S} q_{2 N}$; if both firms engage in FDI then $T_{N}=t_{N}\left(e_{1 N}+e_{1 S}\right)$ and $T_{S}=0$; if only firm $N$ exports then $T_{N}=t_{N}\left(e_{1 N}+e_{2 N}+e_{1 S}\right)$ and $T_{S}=\tau_{S} q_{2 N}$; finally, if only firm $S$ exports then $T_{N}=t_{N} e_{1 N}+\tau_{N} q_{1 S}$ and $T_{S}=0$.

We consider that environmental damage is local. ${ }^{11}$ We use a quadratic functional form to measure the environmental damage generated in country $k$, denoted by $E D_{k}$, due to production operations at the plants located there: $E D_{k}=g\left(E_{k}\right)^{2} / 2$, where $E_{k}$ stands for total emissions in country $k^{12}$ If both firms export then $E_{N}=e_{1 N}+e_{2 N}$ and $E_{S}=e_{1 S}+e_{2 S}$; if both firms engage in FDI then $E_{N}=e_{1 N}+e_{1 S}$ and $E_{S}=e_{2 N}+e_{2 S}$; if only firm $N$ exports then $E_{N}=e_{1 N}+e_{1 S}+e_{2 N}$ and $E_{S}=e_{2 S}$; finally, if only firm $S$ exports then $E_{N}=e_{1 N}$ and $E_{S}=e_{2 N}+e_{2 S}+e_{1 S}$. The positive parameter $g$ measures the valuation of the environment by government $k$ : it can be interpreted as willingness to pay to decrease environmental damage by one unit.

The social welfare function considered by government $k$ comprises the consumer surplus of domestic consumers, $C S_{k}$, the producer surplus of domestic firms, $P S_{k}$, the total 
taxes and tariffs collected by the government (if any), $T_{k}$, and the environmental damage caused by the production process in the country, $E D_{k}$. Specifically, the social welfare function considered by government $k$ can be expressed as:

$$
W_{k}=C S_{k}+P S_{k}+T_{k}-E D_{k}, k=N, S \text {. }
$$

We consider in Section 3 that only the North sets environmental taxes. In order to simplify the exposition of the results, we assume that $g=d=1$. It can be shown that the results obtained in the paper are robust to changes in these parameters.

\section{Only the North sets environmental taxes}

In order to analyze firms' decisions on whether to engage in FDI or not, we propose a three stage game with the following timing. In the first stage, firms decide whether to serve the foreign market by exporting or by setting up a plant there. In the second stage, the government of $N$ sets an environmental tax and the two governments choose import tariffs. Finally, in the third stage firms take production and abatement decisions. The equilibrium concept used is the subgame perfect equilibrium solved by backward induction.

\subsection{Both firms engage in FDI}

In this case firms do not export and so governments do not set tariffs. Firms produce and sell good 1 in country $N$ and good 2 in country $S$. As only the government of $N$ sets an environmental tax, only the plants located in country $N$ abate pollutant emissions and pay taxes. Thus, the profits of the firms are:

$$
\begin{gathered}
\pi_{N}=\left[\left(p_{1}-c\right) q_{1 N}-t_{N} e_{1 N}-a_{1 N}^{2} / 2\right]+\left[p_{2} q_{2 N}\right], \\
\pi_{S}=\left[\left(p_{1}-c\right) q_{1 S}-t_{N} e_{1 S}-a_{1 S}^{2} / 2\right]+\left[p_{2} q_{2 S}\right] .
\end{gathered}
$$

In the third stage, each firm chooses the output and abatement levels of the two plants that maximize its profit. Solving these problems simultaneously gives the following: 


$$
a_{1 k}=t_{N}, q_{1 k}=\frac{\alpha-c-t_{N}}{3}, q_{2 k}=\frac{\alpha}{3}, k=N, S .
$$

Expression (4) shows that $a_{1 k}=t_{N}$, which means that plants located in country $N$ abate pollution to the point where the marginal abatement cost equals the tax (see Ulph, 1996). Expression (4) shows also that an increase in the tax set by the government of $N$, $t_{N}$, raises the abatement level of plant $1 k\left(\partial a_{1 k} / \partial t_{N}>0\right)$ and reduces its output level ( $\left.\partial q_{1 k} / \partial t_{N}<0\right)$. Thus, plant $1 k$ abates more emissions as $t_{N}$ rises to pay lower taxes. Moreover, the output of plant $1 k$ decreases with $t_{N}$ to reduce emissions since it increases production costs.

In the second stage, the government of $N$ sets the environmental tax that maximizes domestic welfare, given by (3) for $k=N$. Solving this problem gives the following.

Lemma 1 When both firms engage in FDI, in equilibrium:

$$
\begin{gathered}
a_{1 N}^{F F}=a_{1 S}^{F F}=t_{N}^{F F}=\frac{16(\alpha-c)}{97}, q_{1 N}^{F F}=q_{1 S}^{F F}=\frac{27(\alpha-c)}{97}, q_{2 N}^{F F}=q_{2 S}^{F F}=\frac{\alpha}{3}, \\
C S_{N}^{F F}=\frac{1458(\alpha-c)^{2}}{9409}, C S_{S}^{F F}=\frac{2 \alpha^{2}}{9}, E D_{N}^{F F}=\frac{242(\alpha-c)^{2}}{9409}, E D_{S}^{F F}=\frac{2 \alpha^{2}}{9}, \\
\pi_{N}^{F F}=P S_{N}^{F F}=\pi_{S}^{F F}=P S_{S}^{F F}=\frac{17122 \alpha^{2}-15426 \alpha c+7713 c^{2}}{84681}, T_{N}^{F F}=\frac{352(\alpha-c)^{2}}{9409}, \\
T_{S}^{F F}=0, W_{N}^{F F}=\frac{322 \alpha^{2}-450 \alpha c+225 c^{2}}{873}, W_{S}^{F F}=\frac{17122 \alpha^{2}-15426 \alpha c+7713 c^{2}}{84681} .
\end{gathered}
$$

\subsection{Firm $\mathrm{N}$ engages in FDI and firm $\mathrm{S}$ exports}

In this case, only firm $N$ sets up a production plant in the foreign country. Firm $S$ has to pay a tariff to export product 1 to country $N$. Thus, the profits of the firms are:

$$
\begin{gathered}
\pi_{N}=\left[\left(p_{1}-c\right) q_{1 N}-t_{N} e_{1 N}-a_{1 N}^{2} / 2\right]+\left[p_{2} q_{2 N}\right], \\
\pi_{S}=\left[\left(p_{1}-\tau_{N}\right) q_{1 S}\right]+\left[p_{2} q_{2 S}\right] .
\end{gathered}
$$


In the third stage, each firm chooses the output and the abatement level of the two plants that maximize its profit. Solving these problems simultaneously gives the following:

$$
a_{1 N}=t_{N}, q_{1 N}=\frac{\alpha-2 c-2 t_{N}+\tau_{N}}{3}, q_{1 S}=\frac{\alpha+c+t_{N}-2 \tau_{N}}{3}, q_{2 N}=q_{2 S}=\frac{\alpha}{3} .
$$

Expression (5) shows that an increase in the tax set by government $N$, $t_{N}$, reduces the output level of plant $1 N\left(\partial q_{1 N} / \partial t_{N}<0\right)$ and increases the output level of its rival $\left(\partial q_{1 S} /\right.$ $\partial t_{N}>0$ ), which is located abroad. This is because only plant $1 N$ pays the tax, which places it at a disadvantage with respect to its rival. Moreover, as only plant $1 S$ pays the tariff set by country $N, \tau_{N}$, that tariff reduces the output level of plant $1 S\left(\partial q_{1 S} / \partial \tau_{N}<0\right)$, the plant that exports, and increases the output level of its rival $\left(\partial q_{1 N} / \partial \tau_{N}>0\right)$.

In the second stage, the government of $N$ sets the environmental tax and the tariff that maximize domestic welfare, given by (3) for $k=N$. Solving this problem gives the following.

Lemma 2 When firm $N$ engages in FDI and firm S exports, in equilibrium:

$$
\begin{gathered}
a_{1 N}^{F E}=t_{N}^{F E}=\frac{2 \alpha-3 c}{17}, \tau_{N}^{F E}=\frac{5 \alpha+c}{17}, q_{1 N}^{F E}=\frac{3(2 \alpha-3 c)}{17}, q_{1 S}^{E F}=\frac{3 \alpha+4 c}{17}, q_{2 N}^{F E}=q_{2 S}^{E F}=\frac{\alpha}{3}, \\
C S_{N}^{F E}=\frac{(9 \alpha-5 c)^{2}}{578}, C S_{S}^{E F}=\frac{2 \alpha^{2}}{9}, E D_{N}^{F E}=\frac{2(2 \alpha-3 c)^{2}}{289}, E D_{S}^{E F}=\frac{(43 \alpha+12 c)^{2}}{5202}, \\
\pi_{N}^{F E}=P S_{N}^{F E}=\frac{1262 \alpha^{2}-2052 \alpha c+1539 c^{2}}{5202}, \pi_{S}^{E F}=P S_{S}^{E F}=\frac{2\left(185 \alpha^{2}+108 \alpha c+72 c^{2}\right)}{2601}, T_{S}^{E F}=0, \\
T_{N}^{F E}=\frac{23 \alpha^{2}-\alpha c+22 c^{2}}{289}, W_{N}^{F E}=\frac{133 \alpha^{2}-144 \alpha c+108 c^{2}}{306}, W_{S}^{E F}=\frac{47 \alpha^{2}-600 \alpha c+144 c^{2}}{5202} .
\end{gathered}
$$

Two cases remained to be solved: in the first both firms export, and in the second firm $N$ exports and firm $S$ engages in FDI. These cases are relegated to Appendixes 1 and 2 , respectively, since they are not sustained in equilibrium. 


\subsection{Export vs. FDI}

It remains to solve the first stage of the game, where firms decide whether to engage in FDI or to export to the other country. Denote $c^{*}=\alpha(360581-11543 \sqrt{857}) / 97129$ $\approx 0.2333 \alpha$. From Lemmas 1 and 2, and Lemmas A1 and A2 (see Appendixes 1 and 2) the following result is obtained.

Proposition 1 In equilibrium if $c<c^{*}$, both firms engage in FDI; if $c \geq c^{*}$, firm $N$ engages in FDI and firm $S$ exports. ${ }^{13}$

Proof See Appendix 3.

It is a dominant strategy for firm $N$ to engage in FDI for all values of parameter $c$. By producing good 2 in the market where it is sold rather than exporting it, firm $N$ reduces production costs and avoids paying tariffs, taxes and abatement costs. Therefore, firm $N$ has a greater market share and makes more profit if produces good 2 in country $S$ than if it exports it.

Whether firm $S$ engages in FDI or exports good 1 depends on parameter $c$. If $c<c^{*}$ then the difference in production costs between the two countries is low enough, and it is a dominant strategy for firm $S$ to engage in FDI. In that case, the tariff paid by the firm when it exports good 1 has a stronger negative effect on profits than the environmental tax, the abatement cost and the greater marginal cost of production that it has to pay when it engages in FDI. Thus, if $c<c^{*}$ both firms engage in FDI which means that each firm locates one plant in each country and the governments do not set tariffs. However, exporting good 1 becomes more attractive for firm $S$ as $c$ increases. Given that firm $N$ engages in FDI, firm $S$ exports if $c \geq c^{*}$; therefore, firm $N$ sets up a plant in each country, firm $S$ exports and the government of $N$ sets a tariff on imports.

\subsection{Welfare analysis}

In this section we assume that there are two main differences between the countries: production costs are higher in country $N$, which is the only country that sets an 
environmental tax. Thus, the results obtained in this section are mainly due to these factors. From Lemmas 1 and 2 the following result is obtained.

Lemma 3 In equilibrium:

i) If $c<c^{*}, P S_{S}^{F F}=P S_{N}^{F F}, C S_{S}^{F F}>C S_{N}^{F F}, E D_{S}^{F F}>E D_{N}^{F F}, T_{N}^{F F}>T_{S}^{F F}=0$;

ii) If $c \geq c^{*}, C S_{S}^{E F}>C S_{N}^{F E}, P S_{N}^{F E}>P S_{S}^{E F}$ if and only if $c<0.2388 \alpha, E D_{S}^{E F}>E D_{N}^{F E}$, $T_{N}^{F E}>T_{S}^{E F}=0$.

\section{Proof See Appendix 4.}

Proposition 1 shows that, in equilibrium, if $c<c^{*}$ both firms engage in FDI. As each firm locates one plant in each country neither firm has an advantage over the other, and the two firms produce the same amount of output and obtain the same profit. Thus, both countries obtain the same producer surplus $\left(P S_{S}^{F F}=P S_{N}^{F F}\right)$. As the plants located in country $N$ have greater marginal production cost, pay environmental taxes and abate emissions, more output is sold in country $S$ than in country $N$, which means that the consumer surplus is greater in country $S\left(C S_{S}^{F F}>C S_{N}^{F F}\right)$. As country $S$ does not protect the environment it suffers greater environmental damage $\left(E D_{S}^{F F}>E D_{N}^{F F}\right)$. Finally, given that there are no tariffs and only the government of $N$ sets a tax: $T_{N}^{F F}>T_{S}^{F F}=0$.

Proposition 1 also shows that, in equilibrium, if $c \geq c^{*}$ firm $N$ engages in FDI and firm $S$ exports. As both firms produce good 2 in country $S$ they sell the same amount of that good $\left(q_{2 S}^{E F}=q_{2 N}^{F E}\right)$. Each firm produces good 1 in its home country. Plant $1 S$ pays a tariff while plant $1 N$ pays an environmental tax, abates emissions and has a higher marginal production cost. The effect of the tariff on profits is weaker and thus plant $1 S$ produces more $\left(q_{1 S}^{E F}>q_{1 N}^{F E}\right)$. Given that total production of good 2 exceeds than that of good 1, country $S$ obtains a greater consumer surplus $\left(C S_{S}^{E F}>C S_{N}^{F E}\right)$. The tariff paid by plant $1 S$ implies that $\pi_{N}^{F E}=P S_{N}^{F E}$ is greater than $\pi_{S}^{E F}=P S_{S}^{E F}$ if and only if $c<0.2388 \alpha$. As there are three plants in country $S$ but just one in country $N$, and only this last plant abates 
emissions, country $S$ suffers greater environmental damage $\left(E D_{S}^{E F}>E D_{N}^{F E}\right)$. Finally, only the government of $N$ sets up a tax and a tariff, so $T_{N}^{F E}>T_{S}^{E F}=0$.

From Lemmas 1 to 3 the following result is obtained.

Proposition 2 In equilibrium, the North obtains greater welfare and suffers less environmental damage than the South.

Proof See Appendix 4.

If $c<c^{*}$ both firms engage in FDI and from Lemmas 1 and 3 it results that country $N$ obtains greater welfare than country $S$. This result is obtained although neither firm has an advantage over its rival: the two markets are of equal size, both firms have a plant in each country and thus they have the same marginal production costs, and they do not pay tariffs since they do not export. This result must therefore be explained by the fact that only the North implements an environmental policy. The lower environmental damage suffered by country $N$ together with the taxes collected by its government (paid partly by firm $S$ ) has a greater effect on social welfare than the lower consumer surplus. Thus, if $c<c^{*}$ country $N$ obtains greater welfare than country $S\left(W_{N}^{F F}>W_{S}^{F F}\right)$.

If $c \geq c^{*}$ firm $N$ engages in FDI and firm $S$ exports and from Lemmas 2 and 3 it results that country $N$ obtains greater welfare than country $S$. In this case only one plant is located in the North, and that plant abates emissions. However, there are three plants located in the South and they do not abate emissions. Although country $N$ obtains a lower consumer surplus, and its producer surplus may be greater or lower, the lower environmental damage suffered by country $N$ together with the tariffs and taxes collected there imply that it obtains greater welfare than country $S\left(W_{N}^{F E}>W_{S}^{E F}\right)$. Therefore, in this case the result is also explained by the fact that the North implements an environmental policy.

\section{Both countries set environmental taxes}


In this section we consider that both countries implement an environmental policy. As in Section 3, the game has three stages, but now in the second stage the two governments set environmental taxes and tariffs simultaneously. Let subscript $t$ denote the fact that both countries set environmental taxes (see Appendix 5). Solving as in Section 3 the following result is obtained.

Proposition 3 When both governments set environmental taxes, in equilibrium both firms engage in FDI. Thus, firms engage in FDI for a greater range of parameter values than when only the North sets an environmental tax.

Proof See Appendix 5.

Proposition 3 shows that compared with the case where only the North protects the environment, the implementation of an environmental policy by the South encourages domestic firms to engage in FDI. If both countries set environmental taxes the effect that makes firm $S$ export when parameter $c$ is great enough disappears. Thus, as firm $S$ now has to pay environmental taxes in both countries, it engages in FDI to avoid the tariff, which has a stronger effect on its profits than the greater marginal production cost incurred in the North. Firm $N$ always engages in FDI to produce at a lower cost and avoid the tariff. As a result, in equilibrium both firms engage in FDI. Thus, when both countries set environmental taxes firms engage in FDI for a greater range of parameter values than when only the North sets a tax.

The effect on the welfare of the countries of stringent environmental policies set by the South remains to be analyzed.

Proposition 4 When both countries set environmental taxes the North obtains lower welfare than the South, and the South (North) obtains greater (lower) welfare than when only the North sets a tax. Moreover, joint welfare is greater when both countries set environmental taxes.

Proof See Appendix 6. 
When both governments set environmental taxes, the South has an advantage over the North since production costs in the North are higher. In this case the two firms locate one plant in each country, so the profit of the firms and thus the producer surplus in the two countries is the same $\left(P S_{S t}^{F F}=P S_{N t}^{F F}\right)$. However, due to the advantage of lower production costs, the output of industry and the consumer surplus in country $S$ is greater $\left(C S_{S t}^{F F}>C S_{N t}^{F F}\right)$ even though the South sets a higher tax than the North. This implies that country $S$ collects more in environmental taxes $\left(T_{S t}^{F F}>T_{N t}^{F F}\right)$ and suffers greater damage $\left(E D_{S t}^{F F}>E D_{N t}^{F F}\right)$. The greater consumer surplus and total taxes in country $S$ offset the greater environmental damage and thus the South obtains greater welfare than the North. Therefore, although the South suffers greater environmental damage than the North it obtains greater welfare.

Next we compare the welfare obtained by the two countries when only the North sets up an environmental tax and when both countries do so. When parameter $c$ is low enough $\left(c<c^{*}\right)$ both firms engage in FDI in both cases. As markets are segmented and the North sets a tax in both cases, it obtains the same consumer surplus $\left(C S_{N}^{F F}=C S_{N t}^{F F}\right)$, suffers the same environmental damage $\left(E D_{N}^{F F}=E D_{N t}^{F F}\right)$ and collects the same amount in taxes $\left(T_{N}^{F F}=T_{N t}^{F F}\right)$ in both cases. However, the producer surplus is lower in the second case $\left(P S_{N}^{F F}>P S_{N t}^{F F}\right)$ : the plant of the Northern firm located in the South pays taxes and thus obtains a lower producer surplus. As a result, the North obtains lower welfare when both governments set environmental taxes since it obtains a lower producer surplus. When the South sets a tax the plants located there pay that tax and abate emissions, so they produce less than when the South does not implement an environmental policy. This means that when the South sets a tax it obtains lower consumer and producer surpluses $\left(C S_{S}^{F F}>C S_{S t}^{F F}, P S_{S}^{F F}>P S_{S t}^{F F}\right)$, collects more in taxes $\left(T_{S}^{F F}<T_{S t}^{F F}\right)$, and suffers lower environmental damage $\left(E D_{S}^{F F}>E D_{S t}^{F F}\right)$. The effect of the lower environmental damage and the greater amount in taxes dominate and thus the South obtains greater welfare when it implements a policy to protect the environment $\left(W_{S}^{F F}<W_{S t}^{F F}\right)$. 
When parameter $c$ is high enough $\left(c>c^{*}\right)$ only the North engages in FDI when the South does not set an environmental tax, and both firms engage in FDI when both governments implement environmental policies. In the first case, the output of the plants of the firms is greater than in the second case. The Southern firm now prefers to engage in FDI since paying a tariff is less attractive; it prefers a high cost of production since it has to pay an environmental tax in both cases. Thus, plant $1 S$ looses market share at the expense of its rival and total production of good 1 decreases. As a result, the North obtains lower consumer and producer surpluses $\left(C S_{N}^{F E}>C S_{N t}^{F F}, P S_{N}^{F E}>P S_{N t}^{F F}\right)$, suffers greater environmental damage $\left(E D_{N}^{F E}<E D_{N t}^{F F}\right)$ and collects more in taxes $\left(T_{N}^{F E}<T_{N t}^{F F}\right)$ when both governments set environmental taxes. Thus, the North obtains lower welfare when both governments implement environmental policies $\left(W_{N}^{F E}>W_{N t}^{F F}\right)$ since consumer and producer surpluses are lower and environmental damage is greater. When the South sets an environmental tax it obtains lower consumer and producer surpluses $\left(C S_{S}^{E F}>C S_{S t}^{F F}, P S_{S}^{E F}>P S_{S t}^{F F}\right)$ than when only the North implements an environmental policy, since the plants located in the South now have greater costs. However, the South collects more in taxes $\left(T_{S}^{E F}<T_{S t}^{F F}\right)$, and suffers lower environmental damage $\left(E D_{S}^{E F}>E D_{S t}^{F F}\right)$; note that now there are two plants that abate emissions in the South while in the other case there are three plants that do not abate emissions. These last effects dominate and thus the South obtains greater welfare when it implements an environmental policy since it suffers less emissions $\left(W_{S}^{F F}<W_{S t}^{E F}\right)$. Finally, although the North obtains lower welfare when both countries set environmental taxes than when only the North implements an environmental policy, joint welfare is greater in the first case.

\section{Conclusions}

Foreign Direct Investment has spread rapidly through the world economy in the past two decades as firms seek, in part, to take advantage of lower costs of product assembly in developing economies and to access new markets. Those economies tend to have lax environmental policies, leaving them at risk of becoming a pollution haven for foreign 
firms. Thus, they need to assess the possibility of implementing environmental policies when foreign polluting firms may locate in their countries.

The relationship between trade and the decision by firms as to where to locate, when firms pollute the environment has been profusely analyzed in the relevant literature. A branch of this literature has analyzed explicitly the linkage between pollution and international trade considering North-South trade. We extend those studies by focusing on relocations that seek to reduce production costs and to access new markets. One contribution of our paper is to consider that both the Southern and the Northern firm may engage in FDI and that both countries set tariffs. Specifically, in this context we analyze the effect that environmental policy implemented by the South has on the location decisions of firms and on social welfare.

We find that when only the North sets an environmental policy both firms engage in FDI if the difference in costs between the two countries is low enough. Otherwise, the Northern firm engages in FDI and the Southern firm exports. Although the North has greater production costs it obtains greater welfare since it implements an environmental policy that reduces its environmental damage. We extend the model to consider that both countries set environmental taxes, and find that both firms always engage in FDI. Thus, environmental policies in the South encourage FDI by domestic firms. Finally, when both countries set environmental taxes the South obtains greater welfare than the North, and the South (North) obtains greater (lower) welfare than when only the North sets environmental taxes. This means that the South could reduce its environmental damage and increase its welfare by taking measures to protect its environment. Moreover, stringent environmental policies by the South do not restrict FDI by Northern firms. Finally, we find that joint welfare is greater when both countries set environmental taxes.

\section{Appendix}

\section{A. 1 Firm $N$ exports and firm $S$ engages in FDI}

Firm $S$ has a production plant in each country. Firm $N$ locates both its plants in country $N$ and pays a tariff to export product 2 . The profits of the firms are: 


$$
\begin{gathered}
\pi_{N}=\left[\left(p_{1}-c\right) q_{1 N}-t_{N} e_{1 N}-a_{1 N}^{2} / 2\right]+\left[\left(p_{2}-c-\tau_{S}\right) q_{2 N}-t_{N} e_{2 N}-a_{2 N}^{2} / 2\right] \\
\pi_{S}=\left[\left(p_{1}-c\right) q_{1 S}-t_{N} e_{1 S}-a_{1 S}^{2} / 2\right]+\left[p_{2} q_{2 S}\right] .
\end{gathered}
$$

In the third stage each firm chooses the output and the abatement level at its two plants that maximize its profit. Solving these problems simultaneously, it is obtained that plant $2 \mathrm{~N}$ abates all emissions; thus: $a_{1 N}=a_{1 S}=t_{N}, \quad q_{1 N}=q_{1 S}=\left(\alpha-c-t_{N}\right) / 3, \quad q_{2 N}=$ $\left(\alpha-2 c-2 \tau_{S}\right) / 5, q_{2 S}=\left(2 \alpha+c+\tau_{S}\right) / 5$. In the second stage, government $S$ chooses the tariff and government $N$ sets the environmental tax that maximizes its own domestic welfare. Solving these problems simultaneously gives the following result.

Lemma A1 When firm $N$ exports and firm $S$ engages in FDI, in equilibrium:

$$
\begin{gathered}
a_{1 N}^{E F}=a_{1 S}^{F E}=t_{N}^{E F}=\frac{16(\alpha-c)}{97}, \tau_{S}^{F E}=\frac{2(\alpha-2 c)}{9}, q_{1 N}^{E F}=q_{1 S}^{F E}=\frac{27(\alpha-c)}{97}, q_{2 S}^{F E}=\frac{4 \alpha+c}{9}, \\
a_{2 N}^{E F}=q_{2 N}^{E F}=\frac{\alpha-2 c}{9}, C S_{N}^{E F}=\frac{1458(\alpha-c)^{2}}{9409}, C S_{S}^{F E}=\frac{(5 \alpha-c)^{2}}{162}, \pi_{N}^{E F}=P S_{N}^{E F}= \\
\frac{55687 \alpha^{2}-130192 \alpha c+83914 c^{2}}{508086}, \pi_{S}^{F E}=P S_{S}^{F E}=\frac{219961 \alpha^{2}-63562 \alpha c+78826 c^{2}}{762129} \\
E D_{N}^{E F}=\frac{242(\alpha-c)^{2}}{9409}, E D_{S}^{F E}=\frac{(4 \alpha+c)^{2}}{162}, T_{N}^{E F}=\frac{352(\alpha-c)^{2}}{9409}, T_{S}^{F E}=\frac{2(\alpha-2 c)^{2}}{81} \\
W_{N}^{E F}=\frac{1447 \alpha^{2}-3088 \alpha c+1738 c^{2}}{5238}, W_{S}^{F E}=\frac{62471 \alpha^{2}-49670 \alpha c+34224 c^{2}}{169362} .
\end{gathered}
$$

A. 2 Both firms export.

Each firm locates its two plants in its home country and both governments set tariffs on imports. The profits of the two firms are:

$$
\begin{gathered}
\pi_{N}=\left[\left(p_{1}-c\right) q_{1 N}-t_{N} e_{1 N}-a_{1 N}^{2} / 2\right]+\left[\left(p_{2}-c-\tau_{S}\right) q_{2 N}-t_{N} e_{2 N}-a_{2 N}^{2} / 2\right], \\
\pi_{S}=\left[\left(p_{1}-\tau_{N}\right) q_{1 S}\right]+\left[p_{2} q_{2 S}\right] .
\end{gathered}
$$

In the third stage, each firm chooses the output and the abatement level of its two plants that maximize its profit. Solving these problems simultaneously gives: $a_{1 N}=a_{2 N}=t_{N}$, 
$q_{1 N}=\left(\alpha-2 c-2 t_{N}+\tau_{N}\right) / 3, q_{2 N}=\left(\alpha-2 c-2 t_{N}-2 \tau_{S}\right) / 3, q_{1 S}=\left(\alpha+c+t_{N}-2 \tau_{N}\right) / 3$, $q_{2 S}=\left(\alpha+c+t_{N}+\tau_{S}\right) / 3$. In the second stage, the two governments choose import tariffs and government $N$ sets the environmental tax that maximizes domestic welfare. Solving these problems gives the following result.

Lemma A2 When both firms export, in equilibrium,

i) If $c<\frac{98 \alpha}{425} \approx 0.2305 \alpha: a_{1 N}^{E E}=a_{2 N}^{E E}=t_{N}^{E E}=\frac{41(2 \alpha-3 c)}{556}, \tau_{N}^{E E}=\frac{43 \alpha+5 c}{139}, \tau_{S}^{E E}=$ $\frac{98 \alpha-425 c}{1112}, q_{1 N}^{E E}=\frac{47(2 \alpha-3 c)}{278}, q_{2 N}^{E E}=\frac{49(2 \alpha-3 c)}{556}, q_{1 S}^{E E}=\frac{98 \alpha+131 c}{556}, q_{2 S}^{E E}=\frac{458 \alpha+147 c}{1112}$, $C S_{N}^{E E}=\frac{(286 \alpha-151 c)^{2}}{618272}, C S_{S}^{E E}=\frac{9(218 \alpha-49 c)^{2}}{2473088}, \pi_{N}^{E E}=P S_{N}^{E E}=\frac{6459(2 \alpha-3 c)^{2}}{154568}$, $\pi_{S}^{E E}=P S_{S}^{E E}=\frac{248180 \alpha^{2}+237356 \alpha c+90253 c^{2}}{1236544}, E D_{N}^{E E}=\frac{3721(2 \alpha-3 c)^{2}}{618272}, E D_{S}^{E E}=$ $\frac{(654 \alpha+409 c)^{2}}{2473088}, T_{N}^{E E}=\frac{26860 \alpha^{2}-5520 \alpha c+25129 c^{2}}{309136}, T_{S}^{E E}=\frac{49(98 \alpha-425 c)(2 \alpha-3 c)}{618272}$, $W_{N}^{E E}=\frac{111988 \alpha^{2}-181396 \alpha c+136047 c^{2}}{309136}, W_{S}^{E E}=\frac{267388 \alpha^{2}-238380 \alpha c+142367 c^{2}}{1236544} ;$

ii) If $c \geq \frac{98 \alpha}{425} \approx 0.2305 \alpha: a_{1 N}^{E E}=a_{2 N}^{E E}=t_{N}^{E E}=\frac{173 \alpha-298 c}{1081}, \tau_{N}^{E E}=\frac{9(37 \alpha+5 c)}{1081}, \tau_{S}^{E E}=0$, $q_{1 N}^{E E}=\frac{356 \alpha-507 c}{1081}, q_{2 N}^{E E}=\frac{245 \alpha-522 c}{1081}, q_{1 S}^{E E}=\frac{7(28 \alpha+33 c)}{1081}, q_{2 S}^{E E}=\frac{418 \alpha+261 c}{1081}, C S_{N}^{E E}=$ $\frac{72(2 \alpha-c)^{2}}{2209}, C S_{S}^{E E}=\frac{9(221 \alpha-87 c)^{2}}{2337122}, \pi_{N}^{E E}=P S_{N}^{E E}=\frac{216690 \alpha^{2}-719872 \alpha c+618337 c^{2}}{1168561}$, $E D_{N}^{E E}=\frac{(255 \alpha-433 c)^{2}}{2337122}, \pi_{S}^{E E}=P S_{S}^{E E}=\frac{2\left(106570 \alpha^{2}+154374 \alpha c+60741 c^{2}\right)}{1168561}$, $E D_{S}^{E E}=\frac{2(307 \alpha+246 c)^{2}}{1168561}, T_{N}^{E E}=\frac{109383 \alpha^{2}-65156 \alpha c+139429 c^{2}}{1168561}, T_{S}^{E E}=0$, $W_{N}^{E E}=\frac{3\left(275 \alpha^{2}-510 \alpha c+433 c^{2}\right)}{2162}, W_{S}^{E E}=\frac{9\left(54317 \alpha^{2}-36974 \alpha c+7669 c^{2}\right)}{2337122}$.

\section{A. 3 Proof of Proposition 1.}


i) As $c<0.2305 \alpha$ : $\pi_{N}^{F E}-\pi_{N}^{E E}=\frac{30332972 \alpha^{2}+43011540 \alpha c-32258655 c^{2}}{402031368}>0, \pi_{N}^{F F}-\pi_{N}^{E F}=$ $\frac{5 \alpha^{2}+4 \alpha c-4 c^{2}}{54}>0, \quad \pi_{S}^{F E}-\pi_{S}^{E E}=\frac{82846279564 \alpha^{2}-259493100652 \alpha c+28687388707 c^{2}}{942406042176}>0$, $\pi_{S}^{F F}-\pi_{S}^{E F}=\frac{162992 \alpha^{2}-721162 \alpha c+97129 c^{2}}{2719201}>0$. Thus, it is a dominant strategy for both firms to engage in FDI.

ii) As $\quad c \geq 0.2305 \alpha: \quad \pi_{N}^{F E}-\pi_{N}^{E E}=\frac{347502602 \alpha^{2}+1346886972 \alpha c-1418173695 c^{2}}{6078854322}>0 \quad$ and $\pi_{N}^{F F}-\pi_{N}^{E F}=\frac{5 \alpha^{2}+4 \alpha c-4 c^{2}}{54}>0 ; \quad \pi_{S}^{F F}-\pi_{S}^{E F}=\frac{162992 \alpha^{2}-721162 \alpha c+97129 c^{2}}{2719201}>0$ if and only if $\quad c<c^{*}=\frac{\alpha(360581-11543 \sqrt{857})}{97129} \approx 0.2333 \alpha \quad$ and $\quad \pi_{S}^{F E}-\pi_{S}^{E E}=$ $\frac{94597671061 \alpha^{2}-309581878774 \alpha c-471965792 c^{2}}{890594226369}>0$ since $c<\bar{c}$. As it is a dominant strategy for firm $N$ to engage in FDI, firm $S$ chooses to export if $c \geq c^{*}$, and to engage in FDI if $c<c^{*}$.

\section{A. 4 Proof of Lemma 3 and Proposition 2.}

As $\quad c<\bar{c}: \quad W_{N}^{F F}-W_{S}^{F F}=\frac{1568(\alpha-c)^{2}}{9409}>0, \quad W_{N}^{F E}-W_{S}^{E F}=\frac{282 c^{2}-308 c \alpha+369 \alpha^{2}}{867}>0, \quad C S_{S}^{F F}-$ $C S_{N}^{F F}=\frac{2(81 c+16 \alpha)(-81 c+178 \alpha)}{84681}>0, C S_{S}^{E F}-C S_{N}^{F E}=\frac{(15 c+7 \alpha)(61 \alpha-15 c)}{5202}>0, E D_{S}^{F F}-E D_{N}^{F F}$ $=\frac{2(33 c+64 \alpha)(-33 c+130 \alpha)}{84681}>0, \quad E D_{S}^{E F}-E D_{N}^{F E}=\frac{(55 \alpha-6 c)(30 c+31 \alpha)}{5202}>0 . \quad$ Finally: $\quad P S_{N}^{F E}-$ $P S_{S}^{E F}=\frac{139 c^{2}-276 c \alpha+58 \alpha^{2}}{578}>0$ if and only if $c<0.2388 \alpha$.

A. 5 Both countries set environmental taxes.

When firm $N$ exports and when it engages in FDI, respectively, its profit is given by:

$$
\begin{gathered}
\pi_{N}=\pi_{1 N}+\pi_{2 N}=\left[\left(p_{1}-c\right) q_{1 N}-t_{N} e_{1 N}-\left(a_{1 N}\right)^{2} / 2\right]+\left[\left(p_{2}-c-\tau_{S}\right) q_{2 N}-t_{N} e_{2 N}-\left(a_{2 N}\right)^{2} / 2\right], \\
\pi_{N}=\pi_{1 N}+\pi_{2 N}=\left[\left(p_{1}-c\right) q_{1 N}-t_{N} e_{1 N}-\left(a_{1 N}\right)^{2} / 2\right]+\left[p_{2} q_{2 N}-t_{S} e_{2 N}-\left(a_{2 N}\right)^{2} / 2\right] .
\end{gathered}
$$

When firm $S$ exports and when it engages in FDI, respectively, its profit is given by: 


$$
\begin{aligned}
& \pi_{S}=\pi_{1 S}+\pi_{2 S}=\left[\left(p_{1}-\tau_{N}\right) q_{1 S}-t_{S} e_{1 S}-\left(a_{1 S}\right)^{2} / 2\right]+\left[p_{2} q_{2 N}-t_{S} e_{2 S}-\left(a_{2 S}\right)^{2} / 2\right] \\
& \pi_{S}=\pi_{1 S}+\pi_{2 S}=\left[\left(p_{1}-c\right) q_{1 S}-t_{N} e_{1 S}-\left(a_{1 S}\right)^{2} / 2\right]+\left[p_{2} q_{2 N} t_{S} e_{2 S}-\left(a_{2 S}\right)^{2} / 2\right]
\end{aligned}
$$

Let subscript $t$ denote that both countries set taxes. When both firms engage in FDI: $t_{N t}^{F F}=\frac{16(\alpha-c)}{97}, \quad t_{S t}^{F F}=\frac{16 \alpha}{97}, \quad \pi_{N t}^{F F}=\pi_{S t}^{F F}=P S_{N t}^{F F}=P S_{S t}^{F F}=\frac{857\left(c^{2}-2 c \alpha+2 \alpha^{2}\right)}{9409}, \quad C S_{N t}^{F F}=$ $\frac{1458(\alpha-c)^{2}}{9409}, C S_{S t}^{F F}=\frac{1458 \alpha^{2}}{9409}, T_{N t}^{F F}=\frac{352(\alpha-c)^{2}}{9409}, T_{S t}^{F F}=\frac{352 \alpha^{2}}{9409}, \quad E D_{N t}^{F F}=\frac{242(\alpha-c)^{2}}{9409}, \quad E D_{S t}^{F F}=$ $\frac{242 \alpha^{2}}{9409}, W_{N t}^{F F}=\frac{2425 c^{2}-4850 c \alpha+3282 \alpha^{2}}{9409}, W_{S t}^{F F}=\frac{857 c^{2}-1714 c \alpha+3282 \alpha^{2}}{9409}$.

When both firms export, plant $2 N$ abates all emissions; thus, if $c>0.2012 \alpha: t_{N t}^{E E}=$ $\frac{3(449 \alpha-612 c)}{10688}, \quad t_{S t}^{E E}=\frac{852 c+1523 \alpha}{10688}, \quad \tau_{N t}^{E E}=\frac{164 c+1303 \alpha}{5344}, \quad \tau_{S t}^{E E}=\frac{21(173 \alpha-212 c)}{10688}, \quad \pi_{N t}^{E E}=$ $\frac{3\left(13374992 c^{2}-17961352 c \alpha+6234689 \alpha^{2}\right)}{114233344}, \quad \pi_{S t}^{E E}=\frac{2975248 c^{2}+7030840 c \alpha+10308177 \alpha^{2}}{57116672}, \quad W_{N t}^{E E}=$ $\frac{3\left(15475312 c^{2}-21851640 c \alpha+12010007 \alpha^{2}\right)}{114233344}, \quad W_{S t}^{E E}=\frac{8930800 c^{2}-2908376 c \alpha+18977239 \alpha^{2}}{57116672} . \quad$ If $c<0.2012 \alpha$, plant $1 S$ abates all emissions; thus: $t_{N t}^{E E}=\frac{4 \alpha-5 c}{31}, t_{S t}^{E E}=\frac{c+4 \alpha}{31}, \tau_{N t}^{E E}=\frac{3 c+10 \alpha}{31}$, $\tau_{S t}^{E E}=\frac{10 \alpha-13 c}{31}, \quad \pi_{N t}^{E E}=\frac{622 c^{2}-886 c \alpha+331 \alpha^{2}}{1922}, \quad \pi_{S t}^{E E}=\frac{67 c^{2}+224 c \alpha+331 \alpha^{2}}{1922}, \quad W_{N t}^{E E}=$ $\frac{767 c^{2}-1118 c \alpha+616 \alpha^{2}}{1922}, W_{S t}^{E E}=\frac{265 c^{2}-114 c \alpha+616 \alpha^{2}}{1922}$.

When firm $N$ engages in FDI and firm $S$ exports plant $1 S$ abates all emissions; thus: $t_{N t}^{F E}=\frac{4 \alpha-5 c}{31}, \quad t_{S t}^{E F}=\frac{16 \alpha}{97}, \quad \tau_{N t}^{F E}=\frac{3 c+10 \alpha}{31}, \quad C S_{N t}^{F E}=\frac{(11 c-15 \alpha)^{2}}{1922}, \quad C S_{S t}^{E F}=\frac{1458 \alpha^{2}}{9409}, \quad \pi_{N t}^{F E}=$ $P S_{N t}^{F E}=\frac{5\left(893855 c^{2}-1430168 c \alpha+901498 \alpha^{2}\right)}{18084098}, \quad \pi_{S t}^{E F}=P S_{S t}^{E F}=\frac{451632 c^{2}+677448 c \alpha+1901197 \alpha^{2}}{18084098}$, $T_{N t}^{F E}=\frac{2 c^{2}-c \alpha+2 \alpha^{2}}{31}, \quad T_{S t}^{E F}=\frac{352 \alpha^{2}}{9409}, \quad E D_{N t}^{F E}=\frac{2(5 c-4 \alpha)^{2}}{961}, \quad E D_{S t}^{E F}=\frac{242 \alpha^{2}}{9409}, \quad W_{N t}^{F E}=$ $\frac{188180 c^{2}-301088 c \alpha+231905 \alpha^{2}}{583358}, W_{S t}^{E F}=\frac{4656 c^{2}+6984 c \alpha+50669 \alpha^{2}}{186434}$.

When firm $N$ exports and firm $S$ engages in FDI, plant $2 N$ abates all emissions; thus: $t_{N t}^{E F}=\frac{16(\alpha-c)}{97}, t_{S t}^{F E}=\frac{1 c+4 \alpha}{31}, \tau_{S t}^{F E}=\frac{10 \alpha-13 c}{31}, \pi_{N t}^{E F}=\frac{3030277 c^{2}-4479842 c \alpha+1901197 \alpha^{2}}{18084098}, \pi_{S t}^{F E}=$ $\frac{5\left(365185 c^{2}-372828 c \alpha+901498 \alpha^{2}\right)}{18084098}, \quad W_{N t}^{E F}=\frac{62309 c^{2}-108322 c \alpha+50669 \alpha^{2}}{186434}, \quad W_{S t}^{F E}=$ $\frac{118997 c^{2}-162722 c \alpha+231905 \alpha^{2}}{583358}$. 
A comparison of the above results leads to the following.
If $c<0.2012 \alpha$ :
(i) $\pi_{N t}^{F F}-\pi$
$\pi_{N t}^{E F}=$
$\frac{-1383123 c^{2}+1185534 c \alpha+1393111 \alpha^{2}}{18084098}, \quad \pi_{N t}^{F E}-\pi_{N t}^{E E}=$
$\frac{-1383123 c^{2}+1185534 c \alpha+1393111 \alpha^{2}}{18084098}$
(ii) $\pi_{S t}^{F F}-\pi_{S t}^{E F}=\frac{1195522 c^{2}-3971756 c \alpha+1393111 \alpha^{2}}{18084098}$,

$\pi_{S t}^{F E}-\pi_{S t}^{E E}=\frac{1195522 c^{2}-3971756 c \alpha+1393111 \alpha^{2}}{18084098}$. These expressions are positive since $c<0.2012 \alpha$. Thus, it is a dominant strategy for both firms to engage in FDI.

If $0.2012 \alpha<c<\bar{c}:$ (i) $\pi_{N t}^{F F}-\pi_{N t}^{E F}=\frac{-1383123 c^{2}+1185534 c \alpha+1393111 \alpha^{2}}{18084098}, \quad \pi_{N t}^{F E}-\pi_{N t}^{E E}=$ $\frac{-107541884863024 c^{2}+78790091866264 c \alpha+88329737559997 \alpha^{2}}{1032903493881856}$, which are positive since $0.2012 \alpha<c<\bar{c}$, implying that it is a dominant strategy for firm $N$ to engage in FDI; (ii) $\pi_{S t}^{F E}-\pi_{S t}^{E E}=\frac{25243041457648 c^{2}-116809936262200 c \alpha+35519372401967 \alpha^{2}}{516451746940928}, \quad \pi_{S t}^{F F}-\pi_{S t}^{E F}=$ $\frac{1195522 c^{2}-3971756 c \alpha+1393111 \alpha^{2}}{18084098}$, which are positive since $0.2012 \alpha<c<\bar{c}$ implying that it is a dominant strategy for firm $S$ to engage in FDI.

As $c<\bar{c}$, then: $W_{S t}^{F F}-W_{N t}^{F F}=\frac{1568 c(2 \alpha-c)}{9409}>0$.

\section{A. 6 Proof of Proposition 4.}

When both countries set environmental taxes and both firms engage in FDI:

$$
\begin{gathered}
\pi_{S t}^{F F}=\pi_{N t}^{F F}=P S_{S t}^{F F}=P S_{N t}^{F F}=\frac{857\left(c^{2}-2 c \alpha+2 \alpha^{2}\right)}{9409}, C S_{S t}^{F F}=\frac{1458 \alpha^{2}}{9409}>C S_{N t}^{F F}=\frac{1458(\alpha-c)^{2}}{9409} \\
E D_{S t}^{F F}=\frac{242 \alpha^{2}}{9409}>E D_{N t}^{F F}=\frac{242(\alpha-c)^{2}}{9409}, T_{S t}^{F F}=\frac{352 \alpha^{2}}{9409}>T_{N t}^{F F}=\frac{352(\alpha-c)^{2}}{9409}
\end{gathered}
$$

Comparing the results obtained when only the North sets a tax with that obtained when both governments set taxes, the following result is obtained.

$$
\begin{aligned}
& \text { If } c<0.2333 \alpha: \quad W_{N}^{F F}-W_{N t}^{F F}=\frac{1696 \alpha^{2}}{84681}>0, \quad W_{S}^{F F}-W_{S t}^{F F}=-\frac{128 \alpha^{2}}{873}<0, \\
& W_{N}^{F F}+W_{S}^{F F}-W_{N t}^{F F}-W_{S t}^{F F}=-\frac{10720 \alpha^{2}}{84681}<0 . \quad \text { If } \quad 0.2333 \alpha<c<\bar{c}: \quad W_{N}^{F E}+W_{S}^{E F}-W_{N t}^{F F}- \\
& W_{S t}^{F F}=\frac{2\left(389214 c^{2}+1366824 c \alpha-3107489 \alpha^{2}\right)}{24472809}<0, W_{N}^{F E}-W_{N t}^{F F}=\frac{274122 c^{2}+129204 c \alpha+247105 \alpha^{2}}{2879154}>0, \\
& W_{S}^{E F}-W_{S t}^{F F}=\frac{-3103218 c^{2}+3270828 c \alpha-16630741 \alpha^{2}}{48945618}<0 .
\end{aligned}
$$




$$
\begin{aligned}
& \text { If } c<0.2333 \alpha: C S_{N}^{F F}=C S_{N t}^{F F}, E D_{N}^{F F}=E D_{N t}^{F F}, T_{N}^{F F}=T_{N t}^{F F}, P S_{N}^{F F}-P S_{N t}^{F F}=\frac{1696 \alpha^{2}}{84681}, \\
& C S_{S}^{F F}-C S_{S t}^{F F}=\frac{5696 \alpha^{2}}{84681}, P S_{S}^{F F}-P S_{S t}^{F F}=\frac{1696 \alpha^{2}}{84681}, E D_{S}^{F F}-E D_{S t}^{F F}=\frac{16640 \alpha^{2}}{84681}, \quad T_{S}^{F F}-T_{S t}^{F F}= \\
& -\frac{352 \alpha^{2}}{9409} . \quad \text { If } \quad 0.2333 \alpha<c<\bar{c}: \quad C S_{S}^{E F}-C S_{S t}^{F F}=\frac{5696 \alpha^{2}}{84681}, \quad C S_{N}^{F E}-C S_{N t}^{F F}= \\
& -\frac{(1403 c-1791 \alpha)(433 c-45 \alpha)}{5438402}>0, \quad P S_{N}^{F E}-P S_{N t}^{F F}=\frac{10022337 c^{2}-10391040 c \alpha+2957930 \alpha^{2}}{48945618}>0, \\
& P S_{S}^{E F}-P S_{S t}^{F F}=\frac{-874161 c^{2}+6490458 c \alpha-976784 \alpha^{2}}{24472809}>0, \quad T_{S}^{E F}-T_{S t}^{F F}=-\frac{352 \alpha^{2}}{9409}, \quad T_{N}^{F E}-T_{N t}^{F F}= \\
& \frac{105270 c^{2}+194047 c \alpha+114679 \alpha^{2}}{2719201}<0, \quad E D_{N}^{F E}-E D_{N t}^{F F}=\frac{2(478 c-381 \alpha)(104 c-7 \alpha)}{2719201}<0, \\
& E D_{S}^{E F}-E D_{S t}^{F F}=\frac{(1164 c+3049 \alpha)(1164 c+5293 \alpha)}{48945618}>0 .
\end{aligned}
$$

\section{Notes}

1 There are a large number of papers that analyze the factors leading firms to engage in FDI but ignore environmental issues. See, for example, Petit and Sanna-Randaccio (2000), Head and Ries (2003), Helpman (2006), Leahy and Naghavi (2010), and Bárcena-Ruiz and Garzón (2014).

2 Some papers analyzing the relationship between FDI and environmental policies find evidence that developing economies are becoming a pollution haven for foreign firms. See, for example, List and Co (2000), Cole and Elliott (2005) and Dean et al. (2009).

${ }^{3}$ An example can be taken from the automobile sector. Although most of the cars manufactured in China are sold within the country, exports totaled 814,300 units in 2011. The PSA Group has several plants in China with an annual production capacity of 600,000 cars (www.psa-peugeot-citroen.com). This group has several plants in the EU to serve this market. Although Chinese producers export cars to the EU, some of them are starting to produce cars there. For example, Geely Motors acquired the European Brand Volvo in 2010 (www.geely.com) and Great Wall Motors has set up a plant in Bulgaria (www.gwmglobal.com). In the coming years they intend to offer a diverse line-up of vehicles on the EU market.

4 We assume that, due to international agreements, countries cannot restrict the way in which firms choose to serve foreign markets (by forbidding imports or FDI, for example).

5 There is evidence that firms from developing countries are acquiring Northern firms and engaging in FDI in the North. In this regard, data from UNCTAD state that in terms of stock the FDI of Chinese firms increased 25\% per annum from 2000 to 2010 . China has been one of the main drivers of outflows from Asia. China moved up from the sixth to the third largest investor in 2012, after the United States and Japan (UNCTAD, 2013).

6 We assume in Section 3 that developed countries set more stringent environmental policies than developing ones. For the sake of simplicity in this section we consider that only the North implements environmental policies. Abe and Zhao (2005) point out that developing countries are reluctant to employ 
stiffer environmental policies for fear of becoming less competitive. Yunfeng and Laike (2010) argue that China's economic growth has been described as an economic miracle, but that it has come at the expense of the environment.

7 Developing countries such as China are starting to set stringent environmental measures. Recently, the Chinese government announced ten air pollution and control measures to combat atmospheric pollution and start solving China's environmental problems (http://www.theclimategroup.org). One of the main measures is a target to reduce emissions from heavily polluting industries by $30 \%$ by 2017 .

8 Tariffs are used by many governments to protect domestic firms. World Tariff Profiles (2012) contains a compilation of the main tariff parameters for each WTO member. Each country profile presents information on tariffs imposed by each economy on imports.

9 The advantage of country $S$ may be due to lower wage costs, abundance of labor that means lower levels of automation of industrial processes with the consequent saving in machinery, or lower prices of raw materials, energy and land.

10 We assume that governments do not subsidize production and thus cannot use tariffs or environmental taxes for that purpose. As a result tariffs and environmental taxes cannot be negative.

11 Environmental damage could comprise, for example, adverse health impacts from water and air pollution, drinking-water shortages associated with water pollution and damage to materials by acid rain. According to a study by the World Bank (2007), the health costs of air and water pollution in China amount to about 4.3 percent of its GDP. If the non-health impacts of pollution, estimated at about 1.5 percent of GDP, are added the total cost of air and water pollution in China is about 5.8 percent of GDP.

12 This type of damage function is commonly used in the relevant literature, and assumes that environmental damage is a convex function of the total pollution level and is exogenous for consumers. See, for example, van der Ploeg and Zeeuw (1992) and Ulph (1996).

13 It can be shown that when governments do not set up tariffs, in equilibrium firm $N$ engages in FDI and firm $S$ exports. In that case, firm $N$ (firm $S$ ) engages in FDI (exports) to avoid paying environmental taxes and abatement costs, and thus produces with the low marginal production cost. Thus, tariffs encourage Southern firms to engage in FDI when parameter $c$ is low enough. On the other hand, if we consider that welfare does not include environmental damage we find that both firms always engage in FDI to avoid tariffs, and to reduce production costs in the case of the Northern firm. 


\section{References}

Abe K, Zhao L (2005) Endogenous international joint ventures and the environment. J Int Econ 67: 221-240.

Bárcena-Ruiz JC, Garzón MB (2003) Strategic environmental standards, wage incomes and the location of polluting firms. Environ Resour Econ 24: 121-139.

Bárcena-Ruiz JC, Garzón MB (2014) Relocation and investment in R\&D by firms. Port Econ J 13: 25-38.

Celik S, Orbay BZ (2011) Location choice under trade and environmental policies. Econ Model 28: 1710-1715.

Chichilnisky G (1994) North-south trade and the global environment. Am Econ Rev 84: 851-874.

Cole MA, Elliott RJR (2005) FDI and the capital intensity of 'dirty' sectors: A missing piece of the pollution have puzzle. Rev Dev Econ 9: 530-48.

Copeland BR, Taylor MS (1994) North-south trade and the environment. Q J Econ 109: $755-787$.

Copeland BR, Taylor MS (1995) Trade and transboundary pollution. Am Econ Rev 85: $716-737$.

Dean JM, Lovely ME, Wang H (2009) Are foreign investors attracted to weak environmental regulations? Evaluating the evidence from China. J Dev Econ 54: 325338.

Head K, Ries J (2003) Heterogeneity and the FDI versus export decision of Japanese Manufacturers. J Jpn Int Econ 17: 448-467.

Helpman E (2006) Trade, FDI, and the organization of firms. J Econ Lit 44: 589-630.

Kayalica MO, Lahiri S (2005) Strategic environmental policies in the presence of foreing direct investment. Env Resour Econ 30: 1-21.

Leahy D, Naghavi N (2010) Intellectual property rights and entry into a foreign market: FDI versus Joint Ventures. Rev Int Econ 18: 633-649.

List JA, Co CY (2000) The effects of environmental regulation on foreign direct investment. J Env Econ Manag 40: 1-2.

Markusen JR (1997) Costly pollution abatement, competitiveness and plant location decisions. Resour Energy Econ 19: 299-320. 
Markusen JR, Morey ER, Olewiler N (1995) Competition in regional environmental policies when plant locations are endogenous. J Public Econ 56: 55-77.

Mody A (2004) Is FDI integrating the world economy? World Econ 27: 1195-1222.

Petit M-L, Sanna-Randaccio F (2000) Endogenous R\&D and foreign direct investment in international oligopolies. Int J Ind Organ 18: 339-367.

Rauscher M (1995) Environmental regulation and the location of polluting industries. Int Tax Public Finan 2: 229-244.

Ulph A (1996) Environmental policy and international trade when governments and producers act strategically. J Env Econ Manag 30: 256-281.

United Nations Conference on Trade and Development (2013) World investment report 2013. Global value chains: Investment and trade for development. United Nations: New York and Geneva.

van der Ploeg F, de Zeeuw A J (1992) International Aspects of Pollution Control. Env Resour Econ 2: 117-139.

World Tariff Profiles (2012) World Trade Organization, the United Nations Conference on Trade and Development (UNCTAD) and the International Trade Centre (ITC).

Yunfeng Y, Laike Y (2010) China's foreign trade and climate change: A case study of $\mathrm{CO}_{2}$ emissions. Energ Policy 38: 350-356.

Wold Bank (2007) Cost of pollution in China. Economic estimates of physical damages, The World Bank, Environmental and Social Development Unit. Available on line at: www.worldbank.org/eapenvironment. 